\section{A retrospective study of the health profile of neonates of mothers with anemia in preg- nancy and pregnancy induced hypertension in Lagos, Nigeria}

Olusola Funmilayo Sotunde,

Silifat Ajoke Sanni, ${ }^{1}$

Oluseye Olusegun Onabanjo, ${ }^{1}$

Ibiyemi O. Olayiwola, ${ }^{1}$ Mure Agbonlahor ${ }^{2}$

${ }^{1}$ Department of Nutrition and Dietetics;

2Department of Agricultural Economics

and Farm Management, College of

Agricultural Management and Rural

Development, University of Agriculture,

Abeokuta, Ogun State, Nigeria

\section{Abstract}

Our study assessed the health profile of neonates in relation to anemia in pregnancy and pregnancy induced hypertension (PIH). This was a retrospective study where a systematic random sampling technique was used to select a total of 1046 case records of pregnant women registered for ante-natal care at Lagos Island Maternity Hospital, Lagos, Nigeria, between 2005 and 2009. Socio-demographic characteristics of the mothers, prevalence of anemia and PIH, and neonatal health profile were obtained from the case records and were analyzed using both descriptive and inferential statistics. Pearson product moment correlation was used to show the relationship $(\mathrm{P} \leq 0.05)$ between maternal complications and neonatal health profile. Majority (68.8\%) of the mothers had anemia and $6.7 \%$ had PIH. Majority $(97.12 \%)$ of the neonates were live births and $2.88 \%$ of the neonates were still births, $65.4 \%$ of the women with still birth pregnancy outcome had anemia, and $34.6 \%$ had PIH. Majority (74\%) of the neonates had birth weight within normal range (2.5-4.0 kg) and majority (68\%) had normal Apgar score at 5 min of birth (710). A positive correlation existed between the packed cell volume of the mother and the birth weight of the neonates $(\mathrm{r}=0.740, \mathrm{P} \leq 0.05)$. A negative correlation existed between the incidence of PIH and the birth weight of the neonates $(r=0.781, P \leq 0.05)$, head circumference $(r=-0.491, P \leq 0.05)$ and the length of the neonates $(r=-0.480, P \leq 0.05)$. We conclude that nutritional and health care intervention programmes for pregnant women should be intensified especially during ante-natal visits to hospitals.

\section{Introduction}

Pregnancy outcomes rank among the most pressing reproductive health problems in the world. ${ }^{1}$ Globally, an annual estimate of 600,000 women aged 15-49 die of pregnancy-related causes, with 99 percent of these coming from the developing world, ${ }^{1-5}$ and Nigeria alone accounting for 10 percent of this total. ${ }^{6}$ Poor nutritional status among pregnant women has been reported to be responsible for the delivery of low birth weight babies and high incidence of anemia. ${ }^{7}$ Maternal and infant mortality depend to a large extent on whether women have access to the information, education and communication resources which they need to provide themselves and their infants with adequate care. ${ }^{8}$ This shows that the achievement of safe motherhood among women results from the interaction of several factors in the relevant societies. Apart from the conditions of health centers and the factors that affect their use or non-use, socioeconomic status of women has also been reported to be strongly associated with pregnancy outcomes. ${ }^{8}$ Anemia in pregnancy is defined by the World Health Organization (WHO) as a hemoglobin concentration below $11 \mathrm{~g} / \mathrm{dL}^{2}$ Anemia in pregnancy is associated with increased rates of maternal and perinatal mortality, premature delivery, low birth weight, and other adverse outcomes. ${ }^{7,9,10}$ Pregnancy induced hypertension (PIH) includes gestational hypertension and preeclampsia or eclampsia. Gestational hypertension, which develops after mid pregnancy, is a maternal blood pressure of $140 / 90 \mathrm{mmHg}$ or higher with no proteinuria. Females with gestational hypertension may develop preeclampsia, which is defined as a systolic blood pressure of 140 $\mathrm{mmHg}$ or higher or a diastolic blood pressure of $90 \mathrm{mmHg}$ and/or a urinary protein level of 300 mg or more in a 24-h urine sample. ${ }^{11} \mathrm{PIH}$ if uncontrolled can damage the liver and kidneys, and both mother and fetus may die. ${ }^{11}$ It is a high risk disorder which occurs in 5\% of pregnancies. ${ }^{12}$ Birth weight, head circumference, and body length of newborn infants are important clinical indicators widely used for evaluation of prenatal growth and identification of infants that require detailed assessment and close monitoring during the neonatal period. Birth weight is classified as very low birth weight (VLBW) <1.5 kg; low birth weight (LBW) 1.5-2.49 kg; normal weight 2.5-4.0 kg; and macrosomic neonates $>4.0 \mathrm{~kg} .{ }^{11}$ Standard references for head circumference and birth length are $32-37 \mathrm{~cm}$ and $46-54 \mathrm{~cm}$ respectively. ${ }^{2}$ The Apgar score was devised in 1952 by Dr. Virginia Apgar as a simple and repeatable method to quickly and summarily assess the health of newborn children immediately after childbirth. ${ }^{13,14}$ Apgar was an anesthesiologist
Correspondence: Olusola Funmilayo Sotunde, Department of Nutrition and Dietetics, College of Food Science and Health Ecology University of Agriculture, Abeokuta (UNAAB), Ogun State. Nigeria. Tel.: $+27781532055 /+2348034460056$. E-mail: solaakinwande@yahoo.com

Key words: health profile, neonates, anemia, pregnancy induced hypertension.

Acknowledgements: the authors will like to acknowledge the contributions of Professor (Mrs.) Clara B. Oguntona for her invaluable help at the onset of this research work. Our appreciation also goes to Dr. Muyiwa Solanke the medical director of Lagos Island maternity hospital for helping the researchers in providing the necessary information.

Contributions: OFS contributed to the study concept and design, acquisition and interpretation of data; SAS, 000, IOA participated in the study concept and revising of the intellectual content of the manuscript; MA participated in the data analysis and interpretation.

Conflict of interests: the authors report no conflict of interests.

Received for publication: 23 October 2012.

Revision received: 13 June 2013.

Accepted for publication: 7 March 2014.

This work is licensed under a Creative Commons Attribution NonCommercial 3.0 License (CC BYNC 3.0).

CC Copyright O.F. Sotunde et al., 2014

Licensee PAGEPress, Italy

Journal of Public Health in Africa 2014; 5:286 doi:10.4081/jphia.2014.286

who developed the score in order to ascertain the effects of obstetric anesthesia on babies. The Apgar score is determined by evaluating the newborn baby on five simple criteria on a scale from zero to two (0 to 2), then summing up the five values thus obtained. The resulting Apgar score ranges from zero to ten (0 to 10). The five criteria (Appearance, Pulse, Grimace, Activity, Respiration) are used as a mnemonic learning aid. The test is generally done at one and five minutes after birth, and may be repeated later if the score is and remains low. Score 3 and below are generally regarded as critically low, 4 to 6 fairly low, and 7 to 10 generally normal. However few studies have been carried out on the prevalence of these complications in relation to the health profile of the neonates in this part of Nigeria. Thus, the aim of this study was to provide information on the prevalence of these complications among pregnant women that registered for ante-natal care at Lagos Island Maternity Hospital Lagos state, Nigeria between 2005 and 2009, and the resultant effects on the neonates. 


\section{Materials and Methods}

\section{Study design/setting}

The study is a retrospective study where data were gathered from case records of 1046 patients who registered for Antenatal care at Lagos Island Maternity Hospital, Campbell Street, Lagos between July 2005 and December 2009. The hospital which is one of the foremost maternity hospitals in Nigeria and in sub-Saharan Africa is owned by Lagos State Government. It is a specialist hospital that caters for all aspects of obstetric and gynecological problems and also a referral secondary centre for many private hospitals, other Lagos State Government Hospitals, and also from tertiary institutions from Lagos environs and other states. Data on age, occupation, marital status, religion, parity, hemoglobin/packed cell volume (PCV) values at registration, and incidence of PIH for the mothers; and birth weight, Apgar score at 5 min after birth, length and head circumference for the neonates were all gathered from the case records. Permission was sought from the hospital authority for access into patients' case records which are in the care of the head of health information and record department of the Hospital.

\section{Sampling selection}

The antenatal department of the hospital keeps a register which has a total of 9695 pregnant women registered for ante natal care at the Hospital within July 2005 and December 2009. The systematic random sampling method with sampling interval of 9 calculated using the Kth element, ${ }^{15}$ random starting point is between 0 and 9 where 6 was randomly picked which became the first number and every $9^{\text {th }}$ number was used. A total number of 1046 case records were selected for the study, excluding case records of women with multiple birth pregnancies as infants of multiple birth pregnancies have a much greater risk of being born premature with intra uterine growth retardation (IUGR) or LBW than do infants of single births. ${ }^{11}$ The case records selected from the register were extracted from the records department.

\section{Data analysis}

Information gathered from the case records were immediately imputed into Excel work sheet with the help of trained research assistants. The Statistical Package for Social Sciences version 16 (SPSS; IBM Corp., Armonk, NY, USA) computer program was used to analyze the data. Descriptive statistics such as frequency and percentage tables were used to describe the distribution of pregnancy complications recorded for the period under consideration and the personal characteristics of the women. Pearson product moment correlation was used to determine the level of relationship and their significance at 5\% probability level $(\mathrm{P} \leq 0.05)$.

\section{Results}

In Table 1, 56.5\% of the pregnant women were in the age range of $20-30$ years, $40.2 \%$ were traders, majority (98.4\%) were married, $53.7 \%$ were Christians, and majority (84.4\%) of the women were between the $0-2$ parity range. Table 2 shows that $68.8 \%$ of the women have anemia, while $6.7 \%$ had pregnancy induced hypertension. It also shows the classification of the anemic status of the pregnant women, PCV values were available for 1001 of the pregnant women out of which most of the women (55.25\%) had mild anemia, 31.17\% were not anemic, $12.39 \%$ had moderate anemia, $1.1 \%$ had severe anemia while $0.09 \%$ had very severe anemia.

In Table 3, majority (92.5\%) of the women less than 20 years old were anemic and none of them had PIH, $69.3 \%$ of the women between 20 and 30 years had anemia while $6.1 \%$ of them had PIH, $69.5 \%$ between the ages of 31 and 40 had anemia and $8.2 \%$ of them had PIH while $53.3 \%$ and $6.7 \%$ between the ages of 41 and 50 had anemia and PIH respectively. Nine hundred and four (904) singleton babies were delivered of the 1046 pregnant women as the remaining 142 mothers did not present at the hospital at the time of birth hence there was no record of the birth of the remaining 142 babies.

In Table 4, ninety-seven percent (97.12\%) of the babies were born alive and $2.88 \%$ were still births. Out of the babies, $52.43 \%$ were male live births and $44.69 \%$ were female live births, with $1.44 \%$ male and female still births each.

Table 5 shows the distribution of pregnancy complications in pregnancy outcome of still birth babies, $65.4 \%$ of these pregnant women had Anemia, and $34.6 \%$ had PIH. In Table 6, majority $(74.3 \%)$ of the neonates had normal birth weight, $15.3 \%$ had LBW and $6.2 \%$ had VLBW, while $4.2 \%$ had high birth weight

Table 1. Socio-demographic data of the pregnant women.

\begin{tabular}{|c|c|}
\hline Variables & $\%(n=1046)$ \\
\hline$<20$ & $40(3.8)$ \\
\hline $20-30$ & $590(56.5)$ \\
\hline $31-40$ & $401(38.3)$ \\
\hline $41-50$ & $15(1.4)$ \\
\hline Total & $1046(100.0)$ \\
\hline \multicolumn{2}{|c|}{ Occupation } \\
\hline Traders & $421(40.2)$ \\
\hline Artisans & $151(14.4)$ \\
\hline Students & $145(13.9)$ \\
\hline Professionals & $236(22.6)$ \\
\hline Unemployed & $93(8.9)$ \\
\hline Total & $1046(100.0)$ \\
\hline \multicolumn{2}{|c|}{ Marital status } \\
\hline Single & $17(1.6)$ \\
\hline Married & 1029 (98.4) \\
\hline Total & $1046(100.0)$ \\
\hline \multicolumn{2}{|c|}{ Religion } \\
\hline Islam & $478(45.7)$ \\
\hline Christianity & $562(53.7)$ \\
\hline Jehovah witness & $6(0.6)$ \\
\hline Total & $1046(100.0)$ \\
\hline \multicolumn{2}{|c|}{ Parity } \\
\hline $0-2$ & $883(84.4)$ \\
\hline $3-5$ & $157(15.0)$ \\
\hline$>6$ & $6(0.6)$ \\
\hline Total & $1046(100.0)$ \\
\hline
\end{tabular}


(macrosomia). Also, 67.9\% of the neonates had normal Apgar score at 5 min of birth, 18.8\% Neonates' Apgar score were critically low, while $13.3 \%$ had fairly low Apgar score..$^{11,13,14}$

In Table 7, 54\% of the neonates were males with mean birth weight of $3.24 \pm 0.57 \mathrm{~kg}$, mean Apgar score of $7.34 \pm 1.38$ at 5 min of birth, mean head circumference of $34.90 \pm 2.41 \mathrm{~cm}$ and mean birth length of $48.46 \pm 3.07 \mathrm{~cm}$, with mean age of the mothers at $29.43 \pm 4.91$ years while $46 \%$ of the neonates were females with mean birth weight of $3.18 \pm 0.54 \mathrm{~kg}$, mean Apgar score at $5 \mathrm{~min}$ of birth of $7.50 \pm 1.20$, mean head circumference of $34.51 \pm 2.40 \mathrm{~cm}$ and mean birth length of $47.62 \pm 3.62 \mathrm{~cm}$ with mean age of their mothers at $29.42 \pm 5$.03years. As evident on the table, majority (84.4\%) of the mothers were within the parity range of 0 -2 with mean age of $28.52 \pm 4.62$ years, the mean birth weight of their neonates was $3.21 \pm 0.53$ $\mathrm{kg}$, their mean Apgar score at 5 min of birth was $7.43 \pm 1.30$, mean head circumference of $34.71 \pm 2.38 \mathrm{~cm}$ and mean birth length of $48.10 \pm 3.47 \mathrm{~cm}$. Also, $15 \%$ of the mothers were within the parity range of 3-5 with mean age of $34.47 \pm 4.21$ years, the mean birth weight of their neonates was $3.21 \pm 0.69 \mathrm{~kg}$, their mean Apgar score at $5 \mathrm{~min}$ of birth was $7.39 \pm 1.27$, mean head circumference of $34.78 \pm 2.65 \mathrm{~cm}$ and mean birth length of $47.86 \pm 4.36 \mathrm{~cm}$. While $0.6 \%$ of the mothers' parity was greater than 6 with mean age of $37.83 \pm 1.60$ years, the mean birth weight of their neonates is $3.33 \pm 0.59 \mathrm{~kg}$, their mean Apgar score at 5 min of birth was $6.17 \pm 1.69$, mean head circumference of $35.00 \pm 0.82 \mathrm{~cm}$ and mean birth length of $49.00 \pm 3.37 \mathrm{~cm}$.

As shown on Table 8, there was a strong positive correlation between the PCV values of the mother and the birth weight of the Neonates while there were strong negative correlations between the incidence of PIH and the birth weight, head circumference and the length of the neonates.

\section{Discussion}

This study assessed the health profile of neonates in relation to anemia in pregnancy and PIH. A relatively high prevalence of anemia in pregnant women in the developing countries has been reported by other studies. ${ }^{10,16-18}$ The $68.8 \%$ prevalence rate of anemia in pregnancy in this study is higher than $40.4 \%$ reported in Enugu, Nigeria ${ }^{9}$ which is similar to the prevalence rate of $39.7 \%$ presented in a study in Benin. ${ }^{19}$ Anemia in pregnancy and PIH has been shown to have the adverse relationship with birth outcome. , $^{9-11}$ According to World Health Organization and Centers for Disease Control and Prevention, ${ }^{20}$ one major
Table 2. Prevalence of pregnancy complications among the women and classification of anemia incidence among the pregnant women.

\begin{tabular}{|cccc}
\hline Complication & Frequency & $\%$ & \\
\hline Anemia & 689 & 68.83 & \\
PIH & 70 & 6.7 & \\
\hline Classification of anemia & Hemoglobin value (g/dL) & Frequency & $\%$ \\
\hline Very severe anemia & $<4$ & 1 & 0.09 \\
\hline Severe anemia & $4-7$ & 11 & 1.1 \\
\hline Moderate & $7.1-9.0$ & 124 & 12.39 \\
\hline Mild & $9.1-10.99$ & 553 & 55.25 \\
\hline Non anemic & 11 and above & 312 & 31.17 \\
Total & & 1001 & 100.0 \\
\hline
\end{tabular}

PIH, pregnancy induced hypertension.

Table 3. Prevalence of pregnancy complications according to the age group of mothers ( \pm standard deviation).

\begin{tabular}{ccc}
$\begin{array}{c}\text { Age range of pregnant } \\
\text { women (years) }\end{array}$ & $\begin{array}{c}\text { Anemia incidence } \\
(\%)\end{array}$ & $\begin{array}{c}\text { Pregnancy induced } \\
\text { hypertension incidence (\%) }\end{array}$ \\
$<20$ & 92.5 & 0 \\
$20-30$ & 69.3 & 6.1 \\
\hline $31-40$ & 69.5 & 8.2 \\
$41-50$ & 53.3 & 6.7 \\
\hline
\end{tabular}

Table 4. Distribution of pregnancy outcome of mothers.

\begin{tabular}{lccc} 
Pregnancy outcome & Gender & Frequency & Percentage (\%) \\
Live birth & Male & 474 & 52.43 \\
& Female & 404 & 44.69 \\
& Total & 878 & 97.12 \\
Still birth & Male & 13 & 1.44 \\
& Female & 13 & 1.44 \\
& Total & 26 & 2.88 \\
\hline \hline Total no. of neonates & & 904 & 100
\end{tabular}

Table 5. Frequency of complications that resulted in still birth.

\begin{tabular}{lcc} 
Complications & Frequency & Percentage \\
Anemia & 17 & 65.4 \\
Pregnancy induced hypertension & 9 & 34.6 \\
\hline
\end{tabular}

Table 6. Distribution of the neonates according to birth weight and Apgar score.

\begin{tabular}{lcc}
\hline & Frequency & Percentage \\
& Range of birth weight of neonates* & \\
Very low $(<1.5 \mathrm{~kg})$ & 56 & 6.2 \\
Low $(1.5-2.49 \mathrm{~kg})$ & 138 & 15.3 \\
\hline Normal $(2.5-4.00 \mathrm{~kg})$ & 672 & 74.3 \\
Macrosomic $(>4.01 \mathrm{~kg})$ & 38 & 4.2 \\
\hline Total & 904 & 100.0 \\
& Range of Apgar score*** & \\
Critically low $(<3)$ & 170 & 18.8 \\
Fairly low $(4$ to 6$)$ & 120 & 13.3 \\
\hline Normal $(7$ to 10$)$ & 614 & 67.9 \\
Total & 904 & 100.0
\end{tabular}

${ }^{*}$ Mahan and Escott-Stump ${ }^{11} ; * *$ Apgar,${ }^{13}$ Finster. ${ }^{14}$ 
Table 7. Health profile of the neonates according to sex and parity ( \pm standard deviation).

\begin{tabular}{|c|c|c|c|c|c|c|c|}
\hline Variabl & equency & Percentage & $\begin{array}{l}\text { Mean } \\
\text { birth weight } \\
\text { of neonate } \\
(\mathrm{kg})\end{array}$ & $\begin{array}{l}\text { Mean Apgar } \\
\text { score of neonate } \\
\text { at } 5 \text { min of birth } \\
\text { Ge }\end{array}$ & $\begin{array}{c}\text { Mean head } \\
\text { circumference } \\
\text { of neonate }(\mathrm{cm})\end{array}$ & $\begin{array}{l}\text { Mean length } \\
\text { of neonate }(\mathrm{cm})\end{array}$ & $\begin{array}{l}\text { Mean age of } \\
\text { mother (years) }\end{array}$ \\
\hline Female & 416 & 46.0 & $3.48 \pm 0.54$ & $7.50 \pm 1.20$ & $34.51 \pm 2.40$ & $47.62 \pm 3.62$ & $29.42 \pm 5.03$ \\
\hline Male & 488 & 54.0 & $3.24 \pm 0.57$ & $7.34 \pm 1.38$ & $34.90 \pm 2.42$ & $48.46 \pm 3.07$ & $29.43 \pm 4.91$ \\
\hline Total & 904 & 100.0 & - & - & - & - & - \\
\hline \multicolumn{8}{|c|}{ Parity } \\
\hline $0-2$ & 883 & 84.4 & $3.21 \pm 0.53$ & $7.43 \pm 1.30$ & $34.71 \pm 2.38$ & $48.10 \pm 3.47$ & $28.52 \pm 4.62$ \\
\hline $3-5$ & 157 & 15.0 & $3.21 \pm 0.69$ & $7.39 \pm 1.27$ & $34.78 \pm 2.65$ & $47.86 \pm 4.36$ & $34.47 \pm 4.21$ \\
\hline$>6$ & 6 & 0.6 & $3.33 \pm 0.59$ & $6.17 \pm 1.69$ & $35.00 \pm 0.82$ & $49.00 \pm 3.37$ & $37.83 \pm 1.60$ \\
\hline Total & 1046 & 100.0 & - & - & - & - & - \\
\hline
\end{tabular}

Table 8. Correlation analysis.

\begin{tabular}{|c|c|c|c|c|c|c|}
\hline Packed cell r & me val & ther & nancy & Pregna & ced h & incidence \\
\hline Variables & $r$ & $\mathbf{P}$ & Decision & r & P & Decision \\
\hline Birth weight & $0.740 *$ & 0.027 & Reject $\mathrm{H}_{0}$ & $-0.781^{* *}$ & 0.00 & Reject $\mathrm{H}_{0}$ \\
\hline Apgar score & 0.019 & 0.583 & Accept $\mathrm{H}_{0}$ & -0.019 & 0.581 & Accept $\mathrm{H}_{0}$ \\
\hline Head circumference & 0.025 & 0.469 & Accept $\mathrm{H}_{0}$ & $-0.491^{* *}$ & 0.001 & Reject $\mathrm{H}_{0}$ \\
\hline Length & 0.046 & 0.173 & Accept $\mathrm{H}_{0}$ & $-0.480 * *$ & 0.000 & Reject $\mathrm{H}_{0}$ \\
\hline
\end{tabular}

${ }^{*}$ Correlation is significant at the 0.05 level (2-tailed); ${ }^{* *}$ correlation is significant at the 0.01 level (2-tailed).

concern about the adverse effects of anemia on pregnant women is the belief that this population is at greater risk of perinatal mortality and morbidity. Our study also has observed an association between maternal anemia in pregnancy with LBW babies and perinatal mortality. Maternal anemia was present in the majority of the birth outcome that resulted in still births, while anemia was responsible for only $3.8 \%$ of still births recorded in a study in Jos, Nigeria. ${ }^{21}$ The anemic women had lower birth weight babies whereby the severity of the anemia corresponds with the birth weight of the neonates in contrast to the Benin study where maternal anemia at delivery had no correspondence to the birth weight of the neonate. ${ }^{19}$ The prevalence rate of $\mathrm{PIH}$ in this study is similar to what has been reported in an American study, ${ }^{22}$ while two South African studies reported a higher rate of $12 \%{ }^{23}$ and $18 \% .^{24}$ Preeclampsia and eclampsia has been linked to fetal death ${ }^{11}$ and this can be one of the reasons why about one third of the mothers who had PIH had still births, while a lower percentage of 6.7 was recorded for still born outcome due to PIH in the Jos study. ${ }^{21}$ This present study further corroborates the results of other studies that PIH causes IUGR and LWB neonates. ${ }^{25,12}$ In a study in Benin City, Nigeria, PIH was the most significant risk factor identified for low birth weight among term singletons, ${ }^{25}$ which supports the strong negative cor- relation between the incidence of PIH and birth weight of the neonate reported in our study. Our study has some limitations, firstly, the gestational age at onset of hypertension in pregnancy and the particular PIH spectrum that were observed were not included in this present study. Secondly, the research was only carried out at one centre therefore conclusions are theoretically limited to this centre. Thirdly, as it is a retrospective study, the information recorded in the case records is our data source for this study therefore our findings will require confirmation in a prospective study.

\section{Conclusions}

This study has showed that anemia in pregnancy and pregnancy induced hypertension are still major problems in Nigeria, as it carries significant risk to mothers and fetus. Hence, the prevention of anemia through health-facility based approach and control package alone may not be effective in combating anemia among pregnant women. Approaches that integrate health and nutrition education into poverty eradication strategies coupled with education on hematinic drug compliance need to be designed, confirmed and adopted, while the importance of constant monitoring should be reiterated for women with PIH.

\section{References}

1. Population Reference Bureau. Making motherhood safer: overcoming obstacles on the pathway to care. Washington, DC: Population Reference Bureau; 2002.

2. World Health Organization. TBAs - an important link in the chain. Safe Motherhood: A Newsletter of Worldwide Activity 2002;29:5.

3. Addai I. Demographic and socio-cultural factors influencing use of maternal health services in Ghana. Afr J Reprod Health 1998;2:74-80.

4. Wall LL. Dead mothers and injured wives: The social context of maternal morbidity and mortality among the Hausa of northern Nigeria. Stud Family Plan 1998;29:341-59.

5. Salter C, Johnston HB, Hengen N. Care for post abortion complications: Saving women's lives. Population Reports. Series L, No. 10. Vol. xxv. Baltimore: Johns Hopkins School of Public Health; 1997.

6. Okolocha C, Chiwuzie J, Braimoh S, et al. Socio- cultural factors in maternal morbidity and mortality: a study of a semi-urban community in Southern Nigeria. J Epidemiol Commun Health 1998;52:293-7.

7. Mohammed AA, Spiekermann-Brouwer GM, Traore AK. Determinants of anemia among pregnant women in Mali. Food Nutr Bull 2006;27:47-9. 
8. WHO, World Bank. Maternal Health around the World: facts and figures. Geneva: World Health Organization; 1997.

9. Dim CC, Onah HE. Prevalence of anemia among pregnant women in South Eastern Nigeria. Med Gen Med 2007;9:11.

10. Nyuke RB, Letsky EA. Etiology of anaemia in pregnancy in South Malawi. Am J Clin Nutr 2000;72:247-56.

11. Mahon KL, Escott-Stump S. Krause's food, nutrition and diet therapy. 11th ed. St Louis, MO: Elsevier Saunders; 2009.

12. Wardlaw GM. Perspectives in nutrition. 4th ed. Boston, MA: WCB McGraw-Hill; 1999.

13. Apgar V. A proposal for a new method of evaluation of the newborn infant. Curr Res Anesth Analg 1953;32:260-7.

14. Finster M, Wood M. The Apgar score has survived the test of time. Anesthesiology 2005;102:855-7.

15. Black K. Business statistics for contemporary decision making. 4 th ed. New Delhi:
Wiley-India; 2004.

16. Ogunbode 0 . Anaemia in pregnancy. In: Okonofua F, Odunsi K, eds. Contemporary obstetrics and gynaecology for developing countries. Benin City: Women's Health and Action Research Center; 2003. pp 514-529.

17. Ilobachie C, Meniru GI. The increasing incidence of anaemia in pregnancy in Nigeria. Orient J Med 1990;2:194-8.

18. Massawe SN, Urassa EN, Nystrom L, Lindmark G. Effectiveness of primary level care in decreasing anemia at term in Tanzania. Acta Obstet Gynecol Scand 1999;78:573-9.

19. Koura GK, Ouedraogo S, Port A, et al. Anaemia during pregnancy: impact on birth outcome and infant haemoglobin level during the first 18 months of life. Trop Med Int Health 2012;17:283-91.

20. WHO/CDC. Assessing the iron status of populations. 2nd ed. Geneva: WHO; 1998.

21. Mutihir J, Eka P. Stillbirths at the Jos
University Teaching Hospital: incidence, risk, and etiological factors. Nig J Clin Pract 2011;20;14.

22. [No authors listed]. ACOG technical bulletin. Hypertension in pregnancy. Number 219--January 1996 (replaces no. 91, February 1986). Committee on Technical Bulletins of the American College of Obstetricians and Gynecologists. Int $\mathrm{J}$ Gynaecol Obstet 1996;53:175-83.

23. Panday M, Mantel GD, Moodley J. Audit of severe acute morbidity in hypertensive pregnancies in a developing country. $\mathrm{J}$ Obstet Gynaecol 2004;24:387-91.

24. Moodley J, Kalane G. A review of the management of eclampsia: practical issues. Hypertens. Pregnancy 2006;25:47-62.

25. Mbazor 0, Umeora 0. Incidence and risk factors for low birth weight among term singletons at the University of Benin Teaching Hospital [UBTH], Benin City, Nigeria. Nig J Clin Pract 2007;10:95-9. 